Laboratory-Clinic Interface

\title{
New insights on PI3K/AKT pathway alterations and clinical outcomes in breast cancer
}

\author{
Sherry X. Yang ${ }^{\text {a,* }}$, Eric Polley ${ }^{\mathrm{b}, 1}$, Stanley Lipkowitz ${ }^{\mathrm{c}}$ \\ a National Clinical Target Validation Laboratory, Division of Cancer Treatment and Diagnosis, National Cancer Institute, National Institutes of Health, Bethesda, MD, USA \\ ${ }^{\mathrm{b}}$ Biometrics Research Branch, Division of Cancer Treatment and Diagnosis, National Cancer Institute, National Institutes of Health, Bethesda, MD, USA \\ ${ }^{\mathrm{c}}$ Women's Malignancies Branch, Center for Cancer Research, National Cancer Institute, National Institutes of Health, Bethesda, MD, USA
}

\section{A R T I C L E I N F O}

\section{Article history:}

Received 21 January 2016

Received in revised form 1 March 2016

Accepted 2 March 2016

\section{Keywords:}

Breast cancer

Chemotherapy

HER2

Paclitaxel

pAKT

PIK3CA mutations

\begin{abstract}
A B S T R A C T
PI3K/AKT signaling pathway plays an important role in tumorigenesis and regulates critical cellular functions including survival, proliferation and metabolism. PIK3CA mutations and AKT activation by phosphorylation (pAKT) are often detected in many cancers and especially at high frequencies in breast cancer. Mounting data suggest that PIK3CA mutations or pAKT are mostly associated with better or insignificant outcomes in estrogen receptor-positive (ER+) early stage breast cancer and tend to be with worse prognosis in ER- disease. pAKT expression has been identified to predict paclitaxel chemotherapy benefit in node-positive breast cancer. Preclinical and neoadjuvant trial data suggest that PIK3CA alterations confer resistance to HER2-targeted therapy and are associated with lower pathological complete response (pCR) rate in HER2-positive breast cancer. However, recent results from randomized clinical trials of adjuvant and metastatic settings show that patients with mutant and wildtype PIK3CA tumors derived similar benefit from anti-HER2 therapy. This article, with our new insights, aims to decipher the mixed data and discusses the influence of the potential confounding factors in the assessments. We also share our views for validation of PI3K/AKT alterations in relation to clinical outcome in the context of specific breast cancer subtypes and treatment modalities towards further advance of the precision medicine for breast cancer treatment.
\end{abstract}

Published by Elsevier Ltd.

\section{Introduction}

Breast cancer is the most commonly diagnosed cancer among women and the second leading cause of cancer death in women in the United States (http://www.cancer.org/Cancer/BreastCancer).

The phosphatidylinositol 3-kinase (PI3Ks) pathway comprises a family of intracellular signal transducer enzymes with three key regulatory nodes $-\mathrm{PI} 3 \mathrm{~K}, \mathrm{AKT}$, and mammalian target of rapamycin (mTOR) [1]. Somatic mutations have been identified in PIK3CA (36\%), PIK3R1 (3\%), PTEN (3\%) and AKT1 (2\%) genes in the pathway, with PIK3CA as the most frequently altered in breast cancer [2]. AKT activation by phosphorylation (pAKT) regulates critical cellular activities such as growth, proliferation, differentiation, metabolism and survival as well as tumorigenesis. Importantly, PI3K/AKT signaling is implicated in the pathogenesis of breast cancer and has

\footnotetext{
* Corresponding author at: Bldg. 37/Rm. 1048, 37 Convent Drive, Bethesda, MD 20892, USA.

E-mail address: Sherry.Yang@nih.gov (S.X. Yang).

${ }^{1}$ Current address: Division of Biomedical Statistics and Informatics, Department of Health Sciences Research, Mayo Clinic, 200 First Street SW, Rochester, MN 55905, USA.
}

been hypothesized to confer resistance to systemic treatments including chemotherapy and HER2-targeted therapy.

The relationship of PIK3CA mutations and AKT activation with prognosis and treatment benefit in breast cancer has been an area of intense investigation with mixed results. Given that chemotherapy and anti-HER2 treatment are standard management in breast cancer and a rapid advance of the targeted approach, it is imperative to diligently interpret the impacts of these alterations on the translational and/or clinical results. Here, we discuss PIK3CA mutations and pAKT for prognosis, and response to or benefit from standard therapy. We review the alterations with an emphasis on the translational research results of the randomized clinical trials in addition to the discussion of the relevant preclinical findings. We also share our views for validation of the pathway biomarkers pertaining to clinical outcomes in the context of specific cytotoxic agents or regimens in breast cancer subtypes.

\section{Breast cancer subtypes and treatment modalities}

Clinically, breast cancer is divided into the subtypes based on biologic or phenotypic markers. Estrogen receptor alpha-positive 
(ER+) and/or progesterone receptor (PR+) - hormone receptorpositive $(\mathrm{HR}+)$ - breast cancer $(\sim 70-75 \%)$ is the most common clinical subtype. Patients with HR+ disease significantly benefit from endocrine therapy [3,4]. Human epidermal growth factor 2positive (HER2+) breast cancer, accounting for about $20 \%$ of all cases of breast cancer, is a particularly aggressive form of breast cancer [5]. HER2+ disease is defined as tumors with either high expression of HER2 protein by immunohistochemistry (IHC) or amplification of HER2 gene by fluorescence hybridization in situ (FISH) [6]. Standard systemic treatment for HER2+ disease includes chemotherapy in combination with HER2-targeted therapy [7]. Approximately half of HER2+ breast cancers are HR+, which are also managed with endocrine therapy. Triple-negative breast cancer (TNBC; ER-, PR- and HER2-) accounts for about $15 \%$ of all breast cancers. There are no approved targeted trerapy for TNBC and the standard treatment is cytotoxic chemotherapy. While the clinical HR+, HER2+ and TNBC subtypes are routinely used for management, breast cancer has been classified into the molecular subtypes by intrinsic gene expression signatures: luminal A (ER+ and HER2-; low proliferative; $~ 50 \%$ ), luminal B (ER+, high proliferative, HER2+ or HER-; 20\%), HER2-type (HER2+, ER+ or ER-; $\sim 15 \%$ ), and basal-like (accounting for the majority of triple- breast cancer; 15\%) [8-10].

\section{PI3K/AKT pathway and alterations}

Class IA PI3K is a heterodimeric lipid kinase consisted of a p110 catalytic subunit encoded by PIK3CA gene and a regulatory p85 subunit by PIK3R1 gene. PI3K is activated in response to a variety of extracellular signals through a receptor tyrosine kinase (RTK) such as HER2, epidermal growth factor receptor (EGFR) or insulin-like growth factor 1 receptor (IGF1R) (Fig. 1A and B). The serine/threonine kinase AKT (protein kinase B) is a downstream multifunctional kinase, which serves as the central mediator of the pathway [11]. Upon activation, p110 PIK3CA phosphorylates phosphatidylinositol $(3,4)$-bisphosphate $\left(\mathrm{PIP}_{2}\right)$ to form phosphatidylinositol $(3,4,5)$-trisphosphate $\left(\mathrm{PIP}_{3}\right)$. Binding of AKT to $\mathrm{PIP}_{3}$ leads to AKT translocation from the cytoplasm to the plasma membrane, where the co-localization of 3-phosphoinositide dependent protein kinase-1 (PDK1) and AKT allows PDK1 to phosphorylate AKT at threonine 308. The full activation of AKT requires AKT to be phosphorylated at serine 473 (pAKT-S473 or pAKT) by mTOR/Rictor complex 2 (mTORC2) [12]. Based on this mechanism of action, antibodies to pAKT-S473 are commonly utilized to evaluate AKT activity [13]. Upon activation, AKT phosphorylates a large number of downstream substrates, which regulate cell growth and protein synthesis by regulating activity of the mTOR/Raptor complex 1 (mTORC1). This increases proliferation/cell-cycle progression. Through GSK-3ß and tau, pAKT regulates microtubule dynamics and organization [14]. PAKT promotes cellular survival via either direct inactivation by phosphorylation of multiple proapoptotic proteins or inhibition of the Forkhead box transcription factors that results in decreased expression of proapoptotic proteins [15]. The characteristic attenuation of apoptosis by pAKT has been hypothesized as a major mechanism of resistance to cancer treatment [16]. The PI3K/AKT pathway is negatively regulated by phosphatase and tensin homolog (PTEN), a lipid phosphatase that dephosphorylates PIP3 [17]. Loss or reduced expression (PTEN low) and function of PTEN occur frequently in breast cancer.

Noticeably, many studies have shown that AKT activity was modulated by chemotherapy agents and other cancer therapeutics [18-20]. Paclitaxel inhibits and doxorubicin augments AKT expression. Table 1 lists the agents that modulate AKT activity in vitro and patients. Of relevance is whether the treatment-induced changes in PAKT have an impact on resistance or sensitivity to specific treatments and long-term clinical outcomes.

Somatic mutations in the PI3K/AKT pathway genes have been identified in significant frequencies in breast cancer. About $90 \%$ of PIK3CA mutations, all missense, were located at hotspot clusters in the helical domain (HD) in exon 9 and kinase domain (KD) in exon 20. The activating mutations H1047R in the KD and E545K and $\mathrm{E} 542 \mathrm{~K}$ in the HD are the most prevalent alterations [21]. PIK3CA is mutated in $230 \%$ of all breast cancers [22]. The mutation frequencies vary by breast cancer subtypes of $34.5-45 \%, 22.7-39 \%$ and $8.3-25 \%$ in HR+, HER2+ and TNBC, respectively [23,24,2,25]. The Cancer Genome Atlas (TCGA) breast cancer analysis found PIK3CA mutation rates of $45 \%$ in luminal A, $29 \%$ in luminal B, 39\% in HER $2+$, and $9 \%$ in the basal-like subtypes [2]. Association of PIK3CA mutations with AKT activation status was observed in some study cohorts [25-27].

\section{PI3K/AKT alterations and prognosis}

A factor for prognosis is defined as the one that is associated with clinical outcome in the absence of therapy or in the context of a standard treatment that all patients likely receive in a disease setting [28]. To date, the relationship between PIK3CA mutations/ pAKT and prognosis are mixed in early breast cancer, some data demonstrating association with favorable outcome, others with poor prognosis, and a number of studies showing insignificant results (Table 2). That PIK3CA mutations or pAKT expression was associated with favorable outcomes has the following features. Over half of each study population received adjuvant endocrine therapy with or without chemotherapy or radiation therapy in studies including all subjects or in those with ER+ disease only (Table 2) [22,29-33]. Furthermore, PIK3CA mutation and a PIK3CA mutant-like expression signature derived from exon 20 PIK3CAmutated tumors was associated with a favorable outcome in ER+ patients who received adjuvant tamoxifen by multivariate analysis [27]. Sabine et al. recently found that PIK3CA was mutated in 40\% of ER+ breast cancer samples in the Tamoxifen Exemestane Adjuvant Multinational (TEAM) phase III trial [33]. The mutations were associated with favorable clinicopathological factors (lower grade, less lymph node involvement, and PR expression), and a better 5year distant relapse-free survival (DRFS). However, PIK3CA mutations were not an independent predictor of outcome in multivariate analysis. Consistent with these results, a recent meta-analysis confirmed that PIK3CA mutations were significantly associated with ER positivity, increasing age, lower grade and smaller tumor size. The genotype was correlated with better invasive diseasefree survival (DFS) by univariate analysis, but not in multivariate analysis [34]. In a neoadjuvant study, PIK3CA KD mutations were prognostic of longer RFS in patients with HR+ tumors after receiving either letrozole or tamoxifen treatment [26]. Together, these results suggest that the clinical outcomes appear to be mostly driven by the intrinsic ER+ tumor characteristics, rather than by activating PIK3CA mutations [35]. Both PI3K and AKT kinases increase ER transcriptional activity in experimental models (Fig. 1A) [36]. MCF-7 cells transfected with an active AKT attenuated apoptosis induced by tamoxifen. However, clinical data may have suggested that the effect of cross-talk between PI3K/AKT signaling and ER could be largely inhibited by adjuvant endocrine therapy administered as a part of systemic therapy in the ER+ breast cancer (Fig. 1A) [27,36]. A recent study by Bosch and colleagues demonstrated that the increase in ER activity following PI3K inhibition could be stimulated by estradiol and suppressed by tamoxifen and fulvestrant in vitro and patient-derived models as well as in tumors from patients [37]. 


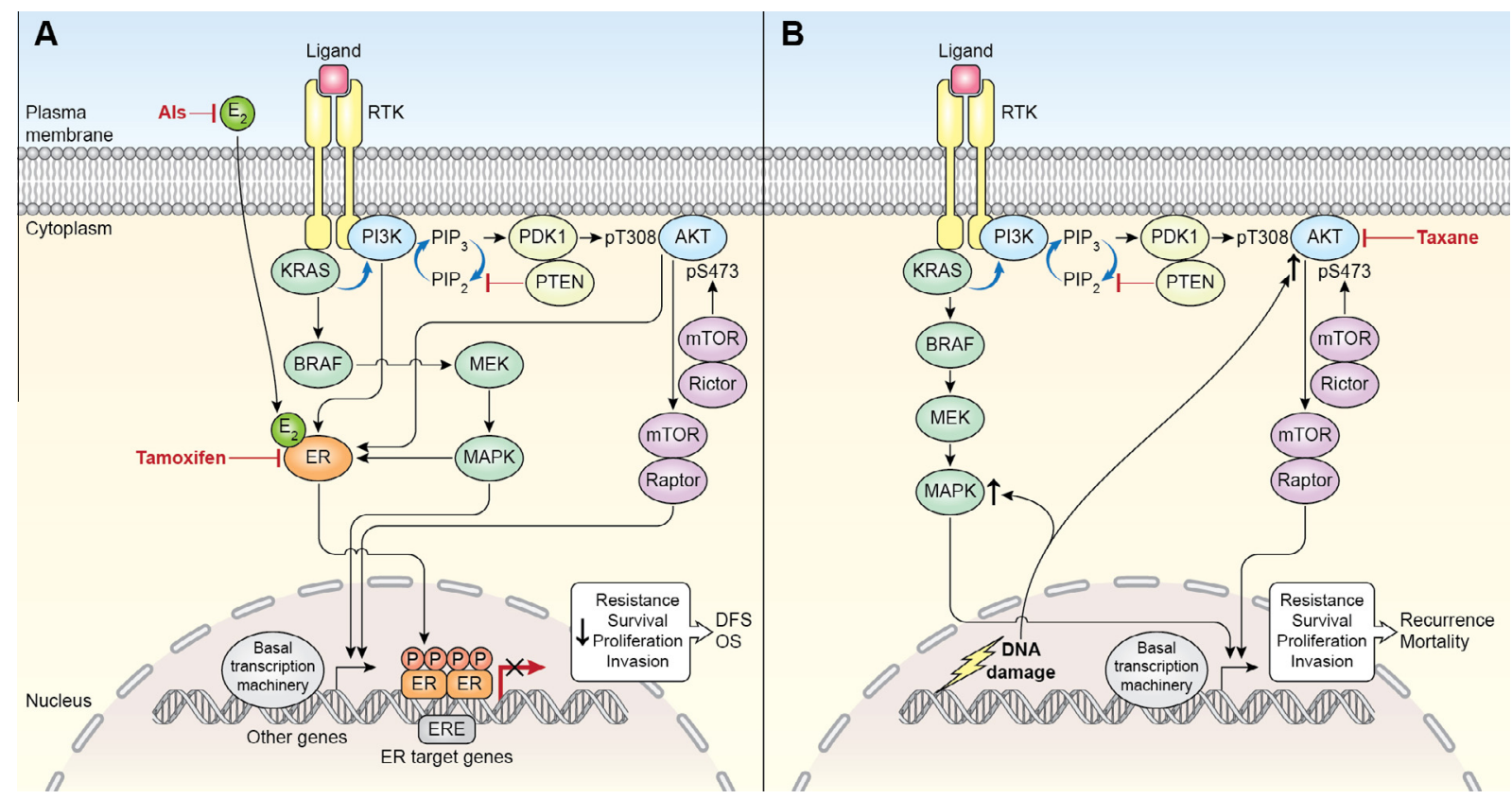

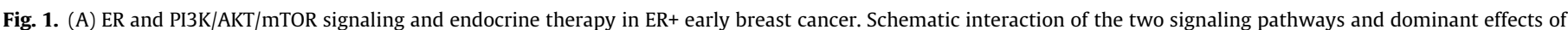

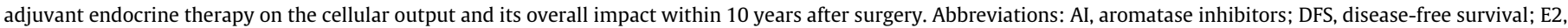

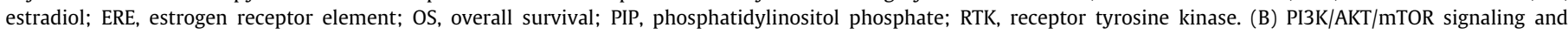

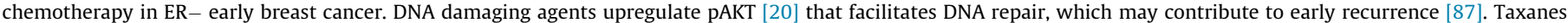
counteract AKT activity at certain extent $[19,50,88]$. Abbreviations: PIP, phosphatidylinositol phosphate; RTK, receptor tyrosine kinase.

Table 1

Anti-cancer agents that modulate AKT activity.

\begin{tabular}{|c|c|c|c|c|}
\hline Drug & Modulation & Dose $(\mu \mathrm{M})$ & In combination & References \\
\hline Paclitaxel & Inhibition & 0.25 & MEK inhibitor & Mackeigan et al. [89] \\
\hline Paclitaxel & Inhibition & 0.05 & Alone & Swanton et al. [19] \\
\hline Paclitaxel & Inhibition & $0.005,0.1$ & Alone & Asakuma et al. [53] \\
\hline Cisplatin & Inhibition & 10 & Alone & Asakuma et al. [53] \\
\hline Topotecan & Inhibition & $0.1,1,10$ & Alone & Nakashio et al. [90] \\
\hline Docetaxel & Inhibition & $0.05,0.075$ & Alone or with $\mathrm{MGd}^{\dagger}$ & Ramos et al. [91] \\
\hline Lapatinib & Inhibition & 1 & Alone & O’Brien et al. [92] \\
\hline Letrozole & Inhibition & $2.5 \mathrm{mg} /$ daily $^{*}$ & Cyclophosphamide & Generali et al. [93] \\
\hline Doxorubicin & Up-regulation & $0.05,0.5,5$ & Alone & Clark et al. [18] \\
\hline
\end{tabular}

* Dose given to patients.

$\dagger$ Abbreviations: MGd, Motexafin gadolinium; NA, not available.

In large studies with all subjects, evaluation of pAKT was not significantly associated with clinical outcomes, suggesting the possibility of confounding factors in the assessments (Table 2) [38-40]. By stratifying ER status, a study analysis recently demonstrated a significant difference for OS in patients with pAKT+ tumors with and without ER expression in doxorubicin-cyclopho sphamide $(A C)$ treatment arm $(P<0.0001)$ and AC followed by paclitaxel group $(P=0.002)$, respectively [41]. Particularly in the AC arm, OS at 10 years was similar in ER+ patients whether pAKT was present or not (77\% in pAKT+ ER+, 75\% in pAKT-ER+ tumors), but was much worse in ER- patients if pAKT was positive (66\% in pAKT - ER - and 58\% in pAKT+ ER - tumors).

Thus, it warrants further investigation for the divergent effects of pAKT on prognosis between ER+ and ER- breast cancers in the context of AC chemotherapy.

As for ER- breast cancer, what role may PIK3CA mutation or AKT activation play? pAKT or combined pAKT and total AKT expression appeared to be associated with unfavorable outcome in ER- disease treated with anthracycline-based chemotherapy (Fig. 1B) $[41,42]$. However, the results need to be validated in studies with sufficient numbers of ER- or TNBC breast cancer patients.

\section{PI3K/AKT alterations and chemotherapy outcome}

Anthracyclines (doxorubicin and epirubicin) are a class of chemotherapy agents that are commonly used for the treatment of breast cancer in the adjuvant and neoadjuvant settings [43]. The agents inhibit topoisomerase II and intercalate into DNA that cause DNA damage to produce cytotoxic effects. Doxorubicin has been shown to induce AKT activation, which mediates resistance to doxorubicin in both ER+ and ER- breast cancer cells $[18,20]$. Brown and colleagues recently reported that MERIT40 phosphorylation by AKT kinase facilitates assembly of the BRCA1 DNA repair complex, which contributes to DNA damage repair and cancer cell survival following doxorubicin treatment [20]. In the MCF7 breast cancer cell line, transfection of HER2 led to an increase in pAKT expression [44], which resulted in cellular resistance to multiple chemotherapy agents including microtubule-stabilizing paclitaxel, DNA-damaging etoposide, camptothecin and doxorubicin, and antimetabolite 5-fluorouracil. However, a subsequent study presented data that constitutive overexpression of HER2 was inadequate to augment pAKT upon exposure to doxorubicin in several HER2+ cell lines [45]. 
Therapy type (\%)

Other relevant information

\begin{tabular}{|c|c|c|c|c|c|c|}
\hline $\begin{array}{l}\text { First author; } \\
\text { year }\end{array}$ & $\begin{array}{l}\text { No. of } \\
\text { patients }\end{array}$ & Alteration (\%) & $\begin{array}{l}\text { Clinical outcome } \mathrm{HR}(95 \% \mathrm{CI}), P \text { value (mut } \\
\text { vs. wt or positive vs. negative) }\end{array}$ & Population & Therapy type (\%) & Other relevant information \\
\hline $\begin{array}{l}\text { Perez-Tenorio } \\
\text { et al. [29] }\end{array}$ & 270 & PIK3CA (24.3) & Longer local RFS, $P=0.023$ & $\begin{array}{l}\text { Postmeno- } \\
\text { pausal }\end{array}$ & $\begin{array}{l}\text { CMF, radiotherapy, } \\
\text { tamoxifen }\end{array}$ & Univariate; associated with ER+ or HER2- status \\
\hline $\begin{array}{l}\text { Maruyama } \\
\text { et al. [30] }\end{array}$ & 188 & PIK3CA (28.7) & RFS $2.34(1.1-5.1), P=0.03$ (wt vs. mut) & All subjects & $\begin{array}{l}\text { Chemotherapy (42.5), EC } \\
\text { (17.5), tamoxifen (78) }\end{array}$ & Multivariate; associated with ER and pAKT expression \\
\hline $\begin{array}{l}\text { Barbareschi } \\
\quad \text { et al. [94] }\end{array}$ & 163 & $\begin{array}{l}\text {-PIK3CA (27.6) } \\
\text {-Exon } 20 \\
\text {-Exon } 9\end{array}$ & $\begin{array}{l}\text {-OS } P=0.75 ; \text { DFS } P=0.61 \\
\text {-Better OS } P=0.01 ; \text { DFS, } P=0.01 \\
\text {-OS 5.32 (2.1-13.2), } P=0.0003 ; \text { DFS } 4.6 \\
(1.8-11.8), P=0.001\end{array}$ & $\begin{array}{l}\text {-All subjects } \\
\text {-All subjects } \\
\text {-All subjects }\end{array}$ & $\begin{array}{l}\text { CMF (30), anthracycline } \\
(17), \\
\text { Anthracycline + taxane (9), } \\
\text { tamoxifen (68), AIs (3) }\end{array}$ & $\begin{array}{l}\text {-Univariate } \\
\text {-Univariate } \\
\text {-Multivariate }\end{array}$ \\
\hline $\begin{array}{l}\text { Liedtke et al. } \\
\text { [47] }\end{array}$ & 140 & PIK3CA (16.4) & pCR $18 \%$ vs. $17 \%, P=1$ & All subjects & $\begin{array}{l}\text {-Neoadjuvant FAC or FEC } \\
(45) \\
\text {-TFAC or TFEC }(55)\end{array}$ & Univariate \\
\hline $\begin{array}{l}\text { Stemke-Hale } \\
\text { et al. [25] }\end{array}$ & 157 & PIK3CA (34.5) & OS, $P=0.597 ;$ RFS, $P=0.919$ & ER+ & Tamoxifen $(100)$ & Univariate \\
\hline $\begin{array}{l}\text { Kalinsky et al. } \\
\text { [31] }\end{array}$ & 520 & PIK3CA (32.5) & $\begin{array}{l}\text { OS } 71 \% \text { vs. } 62 \%, P=0.03 \\
\text { BCSD } 12 \% \text { vs. } 23 \%, P=0.004\end{array}$ & All subjects & Unknown & Univariate; associated with ER expression \\
\hline $\begin{array}{l}\text { Lopez-Knowles } \\
\text { et al. [42] } \\
\text { Loi et al. [82] }\end{array}$ & 292 & $\begin{array}{l}\text { PI3K pathway } \\
\text { PIK3CA-GS }\end{array}$ & BCSD $4.2(1.3-13.6), P=0.02$ & All subjects & $\begin{array}{l}\text { CMF or AC (38); Tamoxifen } \\
\text { (49) }\end{array}$ & Univariate; associated with ER-negative status \\
\hline & $\begin{array}{l}-717 \\
-192 \\
-280 \\
-302\end{array}$ & & $\begin{array}{l}\text {-OS, } 0.7(0.4-1.1), P<0.001 \\
\text {-OS, } 1.3(0.6-2.7), P=0.4 \\
\text {-OS, } 0.7(0.4-1.1), P=0.3 \\
-\mathrm{OS}, 0.5(0.3-0.8), P=0.01\end{array}$ & $\begin{array}{l}\text {-ER+/HER2- } \\
\text {-HER2+ } \\
\text {-Triple- } \\
\text {-ER+ }\end{array}$ & $\begin{array}{l}\text {-No therapy } \\
\text {-No therapy } \\
\text {-No therapy } \\
\text {-Tamoxifen (100) }\end{array}$ & $\begin{array}{l}\text {-Univariate } \\
\text {-Univariate } \\
\text {-Univariate } \\
\text {-Multivariate }\end{array}$ \\
\hline Ellis et al. [26] & $\begin{array}{l}-398 \\
-125 \\
-235\end{array}$ & $\begin{array}{l}\text { PIK3CA (32.0) } \\
- \text { KD } \\
- \text { KD\&HD }\end{array}$ & $\begin{array}{l}\text {-RFS, } 14(1.9-105), P=0.01 \text { (wt vs. mut) } \\
\text {-Negative interaction, } P=0.046\end{array}$ & $\begin{array}{l}-E R+ \\
-E R+\end{array}$ & $\begin{array}{l}\text {-Neoadjuvant endocrine } \\
\text {-Neoadjuvant letrozole }\end{array}$ & $\begin{array}{l}\text {-Multivariate } \\
\text {-Less response to letrozole }\end{array}$ \\
\hline $\begin{array}{l}\text { Dupont Jensen } \\
\text { et al. [95] }\end{array}$ & 104 & PIK3CA (45) & -Longer TTR, $P=0.03$ & All subjects & $\begin{array}{l}\text { Endocrine therapy (52), } \\
\text { chemotherapy (33) }\end{array}$ & Univariate \\
\hline $\begin{array}{l}\text { Ramirez-Ardila } \\
\text { et al. [96] }\end{array}$ & $\begin{array}{l}-1352 \\
-342 \\
-447 \\
-84\end{array}$ & $\begin{array}{l}\text { PIK3CA (31.3) } \\
\text {-Exon } 9 \\
\text {-Exon } 20 \\
\text {-Exon } 9 \\
\text {-Exon } 20 \\
\text {-Exon } 9 \\
\text {-Exon } 20\end{array}$ & $\begin{array}{l}\text {-MFS } 1.04(0.57-1.89), P=0.9 \\
\text {-MFS } 0.98(0.63-1.54), P=0.94 \\
\text {-TTP } 1.17(0.87-1.57), P=0.3 \\
\text {-TTP } 1.01(0.78-1.31), P=0.93 \\
\text {-TTP } 0.4(0.17-0.95), P=0.038 \\
\text {-TTP } 0.5(0.27-0.91), P=0.024\end{array}$ & $\begin{array}{l}\text {-Node- } \\
\text {-Node- } \\
\text {-ER+ } \\
\text { metastatic } \\
\text {-ER+ } \\
\text { metastatic }\end{array}$ & $\begin{array}{l}\text {-No adjuvant therapy } \\
\text {-First line tamoxifen } \\
\text {-First line AIs }\end{array}$ & $\begin{array}{l}\text {-Univariate } \\
\text {-Univariate } \\
\text {-Univariate and multivariate }\end{array}$ \\
\hline $\begin{array}{l}\text { Beelen et al. } \\
\text { [97] }\end{array}$ & 563 & $\begin{array}{l}\text { PIK3CA } \\
\text {-Exon } 9(15.6) \\
\text {-Exon20 }(18.1)\end{array}$ & $\begin{array}{l}-0.82(0.22-3.04), P=0.51 \\
-0.77(0.25-2.36), P=0.51 \\
\text { Tam v control }\end{array}$ & $\begin{array}{l}\text { ER+ } \\
\text { postmenopausal }\end{array}$ & Tamoxifen vs. no treatment & $\begin{array}{l}\text { Adjusted hazard ratios and interaction tests between PIK3CA Exon } 9 \text { or } \\
20 \text { and tamoxifen, respectively }\end{array}$ \\
\hline Stal et al. [98] & 280 & $\begin{array}{l}\text { pAKT, AKT1 and } \\
\text { AKT2 combined (28) }\end{array}$ & Rate ratio 0.5 vs. $1, P=0.04$ & $\begin{array}{l}\text { Postmeno- } \\
\text { pausal }\end{array}$ & $\begin{array}{l}\text { CMF (57); radiotherapy } \\
\text { (43); tamoxifen (49) }\end{array}$ & Multivariate \\
\hline $\begin{array}{l}\text { Kirkegaard } \\
\quad \text { et al. [99] }\end{array}$ & 392 & Cytoplasmic pAKT & Worse OS $1.65(1.0-2.7), P=0.04$ & $\mathrm{ER}+$ & $\begin{array}{l}\text { Tamoxifen (100); } \\
\text { Chemotherapy (24.8); } \\
\text { Radiotherapy (27.6) }\end{array}$ & Univariate after excluding nuclear pAKT \\
\hline $\begin{array}{l}\text { Cicenas et al. } \\
{[100]}\end{array}$ & 156 & pAKT (14) & $2.09(1.14-3.85), P=0.02$ (risk for relapse) & All subjects & Unknown & -Multivariate \\
\hline $\begin{array}{l}\text { Tokunaga et al. } \\
\text { [101] }\end{array}$ & $\begin{array}{l}-252 \\
-107\end{array}$ & pAKT (33) & $\begin{array}{l}-1.3(0.7-2.3), P=0.4(\text { pAKT }- \text { vs. pAKT }+) \\
-2.8(0.9-5.0), P=0.1(\text { pAKT }- \text { vs. pAKT }+)\end{array}$ & $\begin{array}{l}- \text { All subjects } \\
-107\end{array}$ & $\begin{array}{l}\text {-Unknown } \\
\text {-Tamoxifen and/or } \\
\text { goserelin }\end{array}$ & $\begin{array}{l}\text {-Multivariate } \\
\text {-Multivariate }\end{array}$ \\
\hline $\begin{array}{l}\text { Andre et al. } \\
\text { [39] }\end{array}$ & 781 & pAKT (15) & $\begin{array}{l}\text { DFS } 0.99(0.72-1.36), P=0.94 \\
\text { OS } 1.39(0.97-2), P=0.08\end{array}$ & All subjects & $\begin{array}{l}\text {-FAC or FEC ( } 49) \\
\text {-No chemotherapy (51) }\end{array}$ & $\begin{array}{l}\text { Univariate for prognosis; Not predictive to anthracycline-based therapy } \\
\text { (tests for interactions } P=0.73 \text { in } \mathrm{OS} \text { and } P=0.95 \text { in } \mathrm{DFS} \text { ) }\end{array}$ \\
\hline $\begin{array}{l}\text { Badve et al. } \\
\quad[32]\end{array}$ & $\begin{array}{l}-377 \\
-104\end{array}$ & Nuclear pAKT & $\begin{array}{l}\text {-Longer OS, } P=0.004 \\
\text {-Longer OS, } P=0.02\end{array}$ & $\begin{array}{l}-E R+; 100 \\
-E R+/ P R+; 100\end{array}$ & $\begin{array}{l}\text {-Unknown } \\
\text {-Unknown }\end{array}$ & $\begin{array}{l}\text {-Univariate } \\
\text {-Univariate }\end{array}$ \\
\hline
\end{tabular}


Table 2 (continued)

\begin{tabular}{|c|c|c|c|c|c|c|}
\hline $\begin{array}{l}\text { First author; } \\
\text { year }\end{array}$ & $\begin{array}{l}\text { No. of } \\
\text { patients }\end{array}$ & Alteration (\%) & $\begin{array}{l}\text { Clinical outcome } \mathrm{HR}(95 \% \mathrm{CI}), P \text { value (mut } \\
\text { vs. wt or positive vs. negative) })^{\dagger}\end{array}$ & Population & Therapy type (\%) ${ }^{\dagger}$ & Other relevant information \\
\hline Yang et al. [50] & 1581 & pAKT (38) & $\begin{array}{l}\text { DFS: pAKT+: } 0.74 ; P=0.02 \\
\text { pAKT-: } 1.02, P=0.81 \\
\text { OS: pAKT+: } 0.8, P=0.17 \\
\text { pAKT-: } 0.97, P=0.8 \\
(\text { AC-P arm v AC arm) }\end{array}$ & Node+ & $\begin{array}{l}\text { AC (48); AC } \rightarrow \text { paclitaxel } \\
(52) \\
\text { Tamoxifen (83.5) }\end{array}$ & Paclitaxel benefit by multivariate \\
\hline $\begin{array}{l}\text { Hartog et al. } \\
\text { [40] }\end{array}$ & 429 & рAKT & $\begin{array}{l}\text { DFS } 0.78(0.31-1.96), P=0.6 \\
\text { OS } 0.73(0.22-0.38), P=0.5\end{array}$ & All subjects & $\begin{array}{l}\text { HT (35) } \\
\text { Chemotherapy (28) }\end{array}$ & Univariate \\
\hline $\begin{array}{l}\text { Aleskandarany } \\
\text { et al. [38] }\end{array}$ & 1202 & pAKT (76) & $\begin{array}{l}\text { BCSS } P=0.1 \\
\text { MFS } P=0.13\end{array}$ & All subjects & Unknown & Univariate \\
\hline $\begin{array}{l}\text { Cizkovo et al. } \\
\text { [102] }\end{array}$ & 452 & $\begin{array}{l}\text { PIK3CA } \\
(33.4)\end{array}$ & Longer MFS $0.62(0.44-0.87), P=0.006)$ & All subjects & $\begin{array}{l}\text { Radiation (35.4) } \\
\text { Hormone (60) } \\
\text { Chemotherapy (42) }\end{array}$ & Univariate; associates with ER/PR \\
\hline $\begin{array}{l}\text { Bostner et al. } \\
\text { [103] }\end{array}$ & 693 & Nuclear pAKT (28) & $\begin{array}{l}\text { pAKT-: } 0.43(0.28-0.65), P<0.0001 \\
\text { pAKT+: } 0.72(0.39-1.33), P=0.23 \\
\text { (RFS by Tam vs. No tam) }\end{array}$ & $\begin{array}{l}\text { Postmenopa } \\
\text { usal node-- }\end{array}$ & $\begin{array}{l}\text {-Tamoxifen (46); } \\
\text { Radiation }\end{array}$ & Multivariate \\
\hline $\begin{array}{l}\text { Bartlett et al. } \\
\text { [55] }\end{array}$ & 3321 & pAKT (72.0) & No difference in DFS & $\begin{array}{l}\text { High-risk node- } \\
\& \text { node+ }\end{array}$ & $\begin{array}{l}-\mathrm{FEC} \text { or } \mathrm{E} \rightarrow \mathrm{CMF}(50.5) \text {; } \\
\text { FEC } \rightarrow \text { docetaxel (49.5) } \\
\text { Tamoxifen and/or Als (69) }\end{array}$ & Univariate \\
\hline $\begin{array}{l}\text { Sabine et al. } \\
\text { [33] }\end{array}$ & 4272 & PIKЗСА (39.8) & $\begin{array}{l}\text {-DRFS: } 0.76(0.63-0.91), P=0.003 \\
\text {-DRFS: } 0.92(0.75-1.12), P=0.401\end{array}$ & $\begin{array}{l}\text { Postmenopausal } \\
\text { ER+ }\end{array}$ & $\begin{array}{l}\text {-Exemestane (50); } \\
\text { Tamoxifen } \rightarrow \text { exemestane } \\
(50)\end{array}$ & $\begin{array}{l}\text {-Univariate } \\
\text {-Multivariate }\end{array}$ \\
\hline Panget al. [22] & 5719 & $\begin{array}{l}\text { PIK3CA (range } \\
16.4-45 \text { ) }\end{array}$ & $\begin{array}{l}\text { RFS: } 0.76(0.59-0.98), P=0.03 \\
\text { OS: } 1.14(0.72-1.82), P=0.0 .57\end{array}$ & All subjects & NA & -Univariate, associated with ER/PR expression \\
\hline
\end{tabular}

"Full-text studies published in English are included if the patient numbers reach 100 or more, with a focus on those having treatment information; and if pAKT status was examined by immunohistochemistry.

PIK3CA-mutant versus PIK3CA-wildtype or pAKTS473-positive versus pAKTS473-negative unless specifically narrated; adjuvant therapy unless specifically noted in the table.

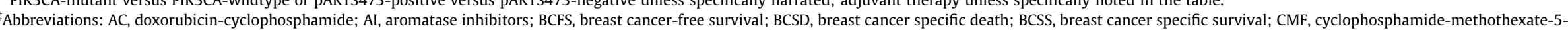

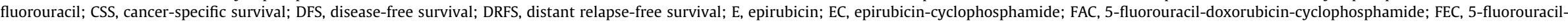

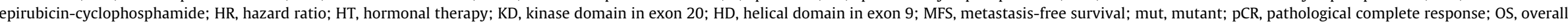

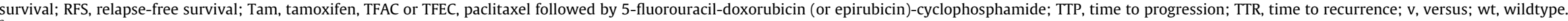
$\S$ PI3K pathway activation status includes PIK3CA mutations and gene copy numbers, pAKT, and PTEN status.

\& PIK3CA-GS, PIK3CA mutation-associated gene signature. 
The treatment benefit can be evaluated through the interaction of a biomarker (predictive biomarker) status and treatment outcomes using any of the clinical endpoints such as response, overall survival (OS), disease-free survival (DFS) or progression-free survival (PFS) [28]. The relative clinical outcomes of the two treatments of comparing a new treatment to control in randomized clinical trials are assessed separately in the biomarker-positive and biomarker-negative patient groups [46].

A prospective-retrospective investigation examined pAKT expression in 823 primary breast tumors from patients who were randomized to receive no treatment or anthracycline-based adjuvant chemotherapy (Table 2). pAKT was neither significantly prognostic of DFS and OS nor predictive of efficacy of anthracyclinebased chemotherapy [39]. The test for interaction was insignificant between pAKT status and efficacy with anthracycline-based chemotherapy. In the neoadjuvant setting, a research team evaluated 140 patients with stage II and III breast cancer and did not observe any association between PIK3CA mutation status and response to neoadjuvant anthracycline- and taxane-containing regimens [47]. Such results were ascribed to a limited number of patients categorized by ER status, mutation types and treatment regimens.

Taxanes including paclitaxel and docetaxel are another class of chemotherapy agents, which primarily stabilize microtubules to inhibit mitosis; they are commonly used for the treatment of breast cancer in all settings. Preclinical data did not demonstrate a clear correlative relationship between PIK3CA or PTEN mutation or AKT activation and paclitaxel (NSC125973) resistance in breast cancer cell lines. These include MCF-7 (PIK3CA-mutant, ER+ and HER2-; Log GI50, -7.9 or $10^{-7.9} \mathrm{M}$ ), MDA-MB-231 (PIK3CA/ PTEN-wildtype, ER - and HER2-; -7.2), T47D (PIK3CA-mutant, ER + and HER2-; -7.0), MDA-MB-468 (PTEN-mutant, ER- and HER2-; -7.7), Hs578T (PIK3CA/PTEN-wildtype, ER - and HER2-; -8.1), and BT549 (PTEN-wildtype, ER- and HER2-; -7.6) (https: //dtp.cancer.gov/dtpstandard/servlet/MeanGraph?searchtype=NS C\&searchlist=125973\&outputformat=HTML\&outputmedium=pag e\&chemnameboolean=AND\&debugswitch=false \&assaytype=\&test shortname $=\mathrm{NCI}+$ Cancer + Screen + Current + Data\&dataarraylength $=6$ 0\&endpt=GI50\&button=Mean + Graph\&highconc $=-5.0$ ). MDA-MB468 cells that express high level of pAKT were more sensitive to paclitaxel than MDA-MB-231cells with low pAKT expression in vitro and in vivo [48].

Recently, pAKT, $1+$ to $3+$ expression detected by IHC (38\%, $606 / 1581$ ), was identified to predict benefit of adding paclitaxel to adjuvant AC chemotherapy. Women with node+ breast cancer were randomly assigned to 4 cycles of adjuvant AC or 4 cycles of AC followed by 4 cycles of paclitaxel chemotherapy in the National Surgical Adjuvant and Bowel Project (NSABP) B28 clinical trial $[49,50]$. In the pAKT+ breast tumors, addition of paclitaxel resulted in a $26 \%$ improvement in DFS and $20 \%$ in OS $[41,50,51]$. By contrast, adding paclitaxel to AC did not lead to any improvement in DFS and OS in patients with pAKT-negative tumors. An apparent interaction was detected between pAKT and treatment with sequential addition of paclitaxel to AC chemotherapy. Since pAKT regulates microtubule dynamics/organization and paclitaxel inhibits AKT phosphorylation, pAKT+ tumors may have incurred more damage from paclitaxel chemotherapy than pAKT - tumors (Table 1; Fig. 1B) [19,52-54].

Recently, Bartlett and colleagues reported that expression of pAKT, p70S6K and p90RSK were not significantly associated with either resistance or sensitivity to docetaxel-based chemotherapy [55]. The United Kingdom Taxotere as Adjuvant Chemotherapy Trial (TACT) tested 4 cycles of 5-fluorouracil, epirubicin and cyclophosphamide (FEC) followed by 4 cycles of docetaxel in comparison with 8 cycles of FEC or 4 cycles of epirubicin followed by 4 cycles of cyclophosphamide, methothexate and 5-flurouracial
(CMF) regimens in the control arm (Table 3) [56]. The study did not identify any trend for interaction between the pathway biomarkers and docetaxel benefit. The analyses of the interactions between PI3K pathway proteins and addition of docetaxel were likely obscured by 4 additional cycles of FEC or CMF in the control arm. Thus, the interaction between the pathway biomarkers and docetaxel data presented can't be directly inferred from the docetaxel only. For analysis of a biomarker-taxane interaction, it would be ideal to compare the addition of a taxane sequentially or concurrently to AC or FAC or FEC regimen in the experimental arm to equal cycle number of $A C$ or FAC or FEC or CMF in the control group $[49,57,58]$. For more guidance, please refer to a recent publication on the "statistical and practical considerations for clinical evaluation of predictive biomarkers" [46]. Table 3 lists the randomized clinical trials with and without a taxane, including those that are ideal for evaluation of the interaction between a biomarker and treatment outcomes.

\section{PI3K/AKT alterations and clinical outcome in HER2+ breast cancer}

HER2 overexpression and signaling result in the activation of two downstream signaling pathways - the RAS/RAF/ERK pathway and the PI3K/AKT pathway. Experimental observations with BT474 (luminal B phenotype) breast cancer cell model demonstrated that HER2+ breast cancer with an activating PIK3CA mutation and low PTEN expression were resistant to HER2-targeted therapy with trastuzumab [59]. Using a genetic approach to search novel modulators of lapatinib resistance in the BT474 breast cancer cells, Eichorn et al. found that loss of PTEN and PIK3CA activating mutations conferred resistance to lapatinib (a dual HER2/HER1 tyrosine kinase inhibitor) [60]. In a transgenic HER2+ mammary tumor mouse model, PIK3CA mutations cooperated with HER2 promoting tumor progression and inducing resistance to trastuzumab alone, and trastuzumab in combination with lapatinib or pertuzumab therapy [61].

In the phase II neoadjuvant Remagus 02 trial, patients with HER2+ breast tumors received epirubicin/cyclophosphamide (EC) preoperatively, and followed by docetaxel and trastuzumab either preoperatively or postoperatively [62]. With a median follow-up of 51 months, DFS was significantly worse in patients with PIK3CAmutant tumors [63]. In a cohort of 240 patients who received adjuvant FEC followed by one year trastuzumab, worse OS and IDFS (invasive disease-free survival) were observed in early stage HER2+ breast cancer patients whose tumors harbor PIK3CA mutations [64]. Recently, results from the phase III CLEOPATRA trial (testing the addition of pertuzumab to docetaxel plus trastuzumab as first line therapy for metastatic breast cancer) showed that PIK3CA activating mutations were associated with a shorter PFS [65]. These data presented evidence of the association between PIK3CA alterations and poor prognosis in early and late stage HER2+ breast cancer. However, it is worthwhile to mention that in metastatic breast cancer with trastuzumab as first-line therapy, loss of PTEN but not PIK3CA mutations or pAKT was significantly associated with a shorter survival, and poor response to trastuzumab alone and to combination of trastuzumab with vinorelbine or taxane-based chemotherapy [66].

In the Neoadjuvant Lapatinib and/or Trastuzumab Treatment Optimization trial (NeoALTTO), patients received lapatinib plus paclitaxel or trastuzumab plus paclitaxel or trastuzumab in combination of lapatinib plus paclitaxel before surgery, followed by FEC chemotherapy plus anti-HER2 agent after surgery [67]. PIK3CA mutations were associated with worse outcome and a lower pCR rate [68]. However, PTEN status failed to distinguish a difference in total PCR to trastuzumab and lapatinib-based therapies [69]. 
Table 3

Randomized Phase III clinical trials that may test the interaction between pAKT or PIK3CA mutations and taxane therapy benefit in breast cancer.

\begin{tabular}{|c|c|c|c|c|c|}
\hline PDQ ID & $\begin{array}{l}\text { ClinicalTrials.gov } \\
\text { ID }\end{array}$ & setting; phase & Regimens & $\begin{array}{l}\text { Enrollment; } \\
\text { population }\end{array}$ & References \\
\hline CALGB 9344 & $\mathrm{~N} / \mathrm{A}$ & Adjuvant, III & $\mathrm{ACx} 4$ vs. $\mathrm{ACx} 4 \rightarrow \mathrm{Px} 4$ & 3121; Node+ & Henderson et al. [57] \\
\hline NSABP B-28 & $\mathrm{N} / \mathrm{A}$ & Adjuvant; III & $\mathrm{ACx} 4$ vs. $\mathrm{ACx} 4 \rightarrow \mathrm{Px} 4$ & $\begin{array}{l}\text { 3050; Node+ } \\
\text { 1581; Node+ }\end{array}$ & $\begin{array}{l}\text { Mamounas et al. [49] } \\
\text { Yang (2010) }\end{array}$ \\
\hline GEICAM 2003-02 & NCT00129389 & Adjuvant; III & $\mathrm{FACx}^{*}$ vs. $\mathrm{FACx} 4 \rightarrow$ wk Px8 & $\begin{array}{l}\text { 1925; high-risk node- } \\
\text { or node+ }\end{array}$ & Martin (2013) \\
\hline FRE-FNCLCC-PACS-01 & $\mathrm{N} / \mathrm{A}$ & Adjuvant; III & FECx6 $6^{*}$ vs. FECx $3 \rightarrow$ Dx3 & 1999; Node+ & Roche (2006) \\
\hline NSABP B-27 & NCT00002707 & $\begin{array}{l}\text { Neoadjuvant \& } \\
\text { adjuvant; III }\end{array}$ & $\begin{array}{l}\text { Pre-surgery ACx } 4 \text { vs. pre-surgery } \\
\mathrm{ACx} 4 \rightarrow \mathrm{Dx} 4 \text { vs. } \\
\mathrm{ACx} 4 \rightarrow \text { post-surgery Dx } 4\end{array}$ & 2411; operable & $\begin{array}{l}\text { Bear }(2003) \\
\text { Bear }[58]\end{array}$ \\
\hline INT-23/96 & NCT00003013 & Adjuvant; III & $\mathrm{Ax} 4 * \mathrm{CMFx} 4$ vs. APx $4 \rightarrow \mathrm{CMFx} 4$ & 1355; Operable & Gianni (2009) \\
\hline TAX_IT1_302 & NCT00174707 & Adjuvant; III & Epidoxorubicin/CMF vs. epidoxorubicin/docetaxel/CMF & 998; node+ & $\mathrm{N} / \mathrm{A}$ \\
\hline TACT & $\mathrm{N} / \mathrm{A}$ & Adjuvant; III & $\mathrm{FECx}^{*}$ or $\mathrm{Ex} 4 \rightarrow \mathrm{CMFx}^{*}$ vs. FECx $4 \rightarrow \mathrm{Dx} 4$ & $\begin{array}{l}4162 \text {; high-risk node- } \\
\text { or node+ }\end{array}$ & $\begin{array}{l}\text { Ellis et al. [56] } \\
\text { Bartlett et al. [55] }\end{array}$ \\
\hline
\end{tabular}

Source: //Clinicaltrials.gov (accessed January 2016).

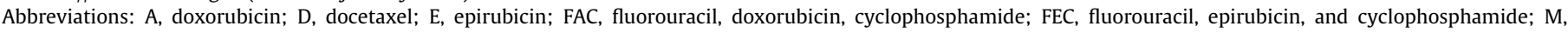
methotrexate; N/A, not available; $P$, paclitaxel; w, weekly; +, positive; -, negative.

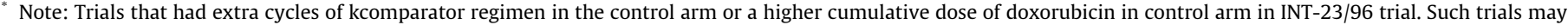
not be ideal to evaluate the interaction between pAKT or PIK3CA mutation and taxane benefit.

Recently, PIK3CA mutations (21.4\%) were evaluated in 504 patient tumors by combining three neoadjuvant trials - GeparQuattro [70], GeparQuinto [71] and GeparSixto [72-74]. HER2+ patients were treated with either trastuzumab or lapatinib plus anthracyclinedocetaxel chemotherapy. The pCR rate was significantly lower in patients with PIK3CA mutations than those without by both univariate and multivariate analyses. However in this study, association of PIK3CA genotype with pCR did not translate into OS and DFS outcomes. Recently, another metaanalysis evaluated pCR rate in 967 patients from GEPAR, NeoALTTO and CHER-LOB trials [75], and found a statistically significant lower pCR rate in HER2+/ PIK3CA-mutant tumors than HER2+/PIK3CA-wildtype tumors $[68,73,76]$. Of note in the evaluation, the pCR rate in PIK3CAmutant tumors was significantly lower than wildtype in HR+ subgroup; in contrast, the difference in PCR rates was not statistically significant in HR- subgroup [77].

Most recently, Slamon and colleagues conducted a combined analysis of the mTOR inhibitor everolimus from the BOLERO-1 and BOLERO-3 clinical trials in patients with locally advanced or metastatic HER2+ breast cancer [78]. The international BOLERO-1 clinical trial enrolled 719 patients with locally advanced or metastatic HER2+ breast cancer and randomized them to paclitaxel plus trastuzumab with or without everolimus as first-line therapy [79]. The BOLERO-3 trial recruited 572 women with locally advanced or metastatic HER2+ breast cancer previously treated with paclitaxel and trastuzumab, who were randomized to vinorelbine plus trastuzumab with or without everolimus [80]. The combined analysis demonstrated a significant PFS benefit in patients with PIK3CAmutant or PTEN loss/low tumors treated with everolimus in combination with trastuzumab plus either paclitaxel or vinorelbine. By contrast, an everolimus benefit was not seen in patients with PIK3CA wildtype or PTEN normal status. These results are the first to demonstrate that PIK3CA mutations and/or PTEN loss predict everolimus efficacy in patients with advanced HER2+ breast cancer.

As for the predictive value of the PI3K/AKT pathway alterations to HER2-targeted therapy, several studies using samples from randomized clinical trials showed comparable results in patients with both PIK3CA-mutant and PIK3CA-wildtype tumors. Patients were randomly assigned to receive or not to receive nine weekly trastuzumab infusions after adjuvant chemotherapy with docetaxel or vinorelbine, followed by FEC in those with HER2+ disease in FinHER phase III trial [81]. There were no significant interactions between PIK3CA mutations and distant DFS or OS [82]. In NSABP
B31 trial, all patients were randomly assigned to AC followed by paclitaxel chemotherapy with and without trastuzumab. PogueGeile and colleagues recently analyzed tumor PIK3CA mutation status and reported that patients with both PIK3CA- mutated and wildtype HER2+ tumors similarly benefited from adjuvant trastuzumab [83]. In analysis of specimens from the BCIRG-005 and BCIRG-006 clinical trials [7,84], PTEN loss was associated with worse DFS and OS in HER2+ disease [85]. However, patients with PTEN- tumors, as those with PTEN+ tumors, also benefited from adjuvant trastuzumab. Extending this trend from the adjuvant setting, PIK3CA mutations were found not predictive of treatment resistance or benefit from addition of pertuzumab to trastuzumab/docetaxel regimen in HER2+ metastatic breast cancer [65]. The biomarker analysis in the EMILIA study also did not find an association between PIK3CA mutations and response to trastuzumab-emtansine conjugate (T-DM1) therapy in patients with HER2+ locally advanced or metastatic breast cancer [86].

Hence, mounting evidence from the randomized clinical studies has challenged the role of PI3K/AKT alterations to anti-HER2 therapy resistance or confounded by some cytotoxic treatment. PIK3CA mutations are mostly associated with poor prognosis and lower pCR rate in patients treated with neadjuvant chemotherapy in combination with trastuzumab and/or lapatinib in HER2+ breast cancer. The impact of administration sequence of paclitaxel and anthracycline-based chemotherapy or paclitaxel versus docetaxel or vinorelbine with regard to PI3K/AKT alterations on the clinical outcome remains to be determined.

\section{Conclusions}

PI3K/AKT pathway is of critical importance in breast cancer pathogenesis unraveled after research spanning over several decades; nonetheless, data has been mixed for its implications in patient outcomes. As discussed, the factors complicating the translation primarily are (i) heterogeneous breast cancer population whose tumors may differ in the magnitude of dependence on the PI3K/AKT signaling or received different treatments; (ii) some and evolving treatment modalities that may have altered this pathway activity. As such, results were inconsistent with regard to PIK3CA mutations or AKT activation for prognosis in early stage breast cancer. These alterations were mostly associated with better or insignificant outcome in ER+ population and tend to be with worse outcome in ER- disease. Adjuvant endocrine therapy is 
effective, which may have largely overridden the effects of the PI3K/AKT pathway signaling in ER+ early breast cancer.

pAKT is identified to predict paclitaxel benefit in node+ breast cancer and the results on taxane benefit could be validated using samples from the randomized clinical trials listed in Table 3 or prospectively designed clinical trials. The question remains on whether anthracycline-based chemotherapy led to different outcomes with regard to AKT activation in ER+ and ER- breast cancers, respectively. It is important to determine if the alteration is a negative predictor to anthracycline-based chemotherapy in patients with ER- disease using sample sizes with adequate statistical power. Taxanes are the agents of choice in combination with trastuzumab or lapaninib. It is important to test their addictive effect with HER2-targeted agents in terms of inhibition of the PI3K/AKT signaling.

There have been challenges to retrospectively evaluate the interaction of a biomarker with the drug for treatment outcome in the randomized clinical trials. The elements that influence this type of analysis include (i) many of the conventionally designed treatment trials are not ideal or suitable to evaluate biomarkerdrug interaction; (ii) modulation of the central mediator of PI3K pathway, AKT activity, by some chemotherapy or hormonal agents may have substantial impact on clinical outcome. In addition, (iii) much data have pointed out PI3K/AKT alterations in connection with the ER status that have impact on clinical outcome. The data may have implications on the choice of chemotherapy agents and other cancer therapeutics according to the ER status, shedding light on further advance of precision medicine in breast cancer treatment.

\section{Conflict of interest}

Dr. Sherry Yang is one of the inventors on the United States National Institutes of Health patent - US 8,546,091 B2. Drs. Polley and Lipkowitz declare no conflicts of interest.

\section{Acknowledgments}

Supported in part by the Division of Cancer Treatment and Diagnosis and the Center for Cancer Research of the National cancer Institute, National Institutes of Health, USA.

\section{References}

[1] Whitman M, Downes CP, Keeler M, Keller T, Cantley L. Type I phosphatidylinositol kinase makes a novel inositol phospholipid, phosphatidylinositol-3-phosphate. Nature 1988;332:644-6.

[2] Comprehensive molecular portraits of human breast tumours. Nature 2012;490:61-70.

[3] Davies C et al. Relevance of breast cancer hormone receptors and other factors to the efficacy of adjuvant tamoxifen: patient-level meta-analysis of randomised trials. Lancet 2011:378:771-84.

[4] Dowsett M et al. Meta-analysis of breast cancer outcomes in adjuvant trials of aromatase inhibitors versus tamoxifen. J Clin Oncol 2010;28:509-18.

[5] Slamon DJ et al. Studies of the HER-2/neu proto-oncogene in human breast and ovarian cancer. Science 1989;244:707-12.

[6] Wolff AC et al. Recommendations for human epidermal growth factor receptor 2 testing in breast cancer: American society of clinical oncology/ College of American pathologists clinical practice guideline update. J Clin Oncol 2013;31:3997-4013.

[7] Slamon D et al. Adjuvant trastuzumab in HER2-positive breast cancer. N Engl J Med 2011;365:1273-83.

[8] Carey LA et al. Race, breast cancer subtypes, and survival in the Carolina breast cancer study. JAMA 2006;295:2492-502.

[9] Onitilo AA, Engel JM, Greenlee RT, Mukesh BN. Breast cancer subtypes based on ER/PR and Her2 expression: comparison of clinicopathologic features and survival. Clin Med Res 2009;7:4-13.

[10] Cheang MC et al. Ki67 index, HER2 status, and prognosis of patients with luminal B breast cancer. J Natl Cancer Inst 2009;101:736-50.

[11] Franke TF, Kaplan DR, Cantley LC, Toker A. Direct regulation of the Akt protooncogene product by phosphatidylinositol-3,4-bisphosphate. Science 1997;275:665-8.
[12] Sarbassov DD, Guertin DA, Ali SM, Sabatini DM. Phosphorylation and regulation of Akt/PKB by the rictor-mTOR complex. Science 2005;307:1098-101.

[13] Badve S, Nakshatri $H$. Role of AKT isotypes in breast cancer. J Pathol 2013;229:e1.

[14] Goold RG, Owen R, Gordon-Weeks PR. Glycogen synthase kinase 3beta phosphorylation of microtubule-associated protein $1 \mathrm{~B}$ regulates the stability of microtubules in growth cones. J Cell Sci 1999;112(Pt 19):3373-84.

[15] Brunet A et al. Akt promotes cell survival by phosphorylating and inhibiting a Forkhead transcription factor. Cell 1999;96:857-68.

[16] Osborne CK, Schiff R, Fuqua SA, Shou J. Estrogen receptor: current understanding of its activation and modulation. Clin Cancer Res 2001;7:4338s-42s. discussion 4411s-4412s.

[17] Hollander MC, Blumenthal GM, Dennis PA. PTEN loss in the continuum of common cancers, rare syndromes and mouse models. Nat Rev Cance 2011:11:289-301.

[18] Clark AS, West K, Streicher S, Dennis PA. Constitutive and inducible Akt activity promotes resistance to chemotherapy, trastuzumab, or tamoxifen in breast cancer cells. Mol Cancer Ther 2002;1:707-17.

[19] Swanton C et al. Regulators of mitotic arrest and ceramide metabolism are determinants of sensitivity to paclitaxel and other chemotherapeutic drugs. Cancer Cell 2007;11:498-512.

[20] Brown KK, Montaser-Kouhsari L, Beck AH, Toker A. MERIT40 is an Akt substrate that promotes resolution of DNA damage induced by chemotherapy. Cell Rep 2015;11:1358-66.

[21] Samuels Y et al. High frequency of mutations of the PIK3CA gene in human cancers. Science 2004;304:554.

[22] Pang B et al. Prognostic role of PIK3CA mutations and their association with hormone receptor expression in breast cancer: a meta-analysis. Sci Rep 2014;4:6255.

[23] Saal LH et al. PIK3CA mutations correlate with hormone receptors, node metastasis, and ERBB2, and are mutually exclusive with PTEN loss in human breast carcinoma. Cancer Res 2005;65:2554-9.

[24] Karakas B, Bachman KE, Park BH. Mutation of the PIK3CA oncogene in human cancers. Br J Cancer 2006;94:455-9.

[25] Stemke-Hale K et al. An integrative genomic and proteomic analysis of PIK3CA, PTEN, and AKT mutations in breast cancer. Cancer Res 2008;68:6084-91.

[26] Ellis MJ et al. Phosphatidyl-inositol-3-kinase alpha catalytic subunit mutation and response to neoadjuvant endocrine therapy for estrogen receptor positive breast cancer. Breast Cancer Res Treat 2010;119:379-90.

[27] Loi S et al. PIK3CA mutations associated with gene signature of low mTORC1 signaling and better outcomes in estrogen receptor-positive breast cancer. Proc Natl Acad Sci U S A 2010;107:10208-13.

[28] McShane LM, Korn EL, Freidlin B. In: Yang SX, Dancey JE, editors. Handbook of therapeutic biomarkers in cancer. Singapore: Pan Stanford Publishing Pte. Ltd; 2013. p. 1-490.

[29] Perez-Tenorio G et al. PIK3CA mutations and PTEN loss correlate with similar prognostic factors and are not mutually exclusive in breast cancer. Clin Cancer Res 2007;13:3577-84.

[30] Maruyama N et al. Clinicopathologic analysis of breast cancers with PIK3CA mutations in Japanese women. Clin Cancer Res 2007;13:408-14.

[31] Kalinsky $\mathrm{K}$ et al. PIK3CA mutation associates with improved outcome in breast cancer. Clin Cancer Res 2009;15:5049-59.

[32] Badve S et al. Subcellular localization of activated AKT in estrogen receptorand progesterone receptor-expressing breast cancers: potential clinical implications. Am J Pathol 2010;176:2139-49.

[33] Sabine VS et al. Mutational analysis of PI3K/AKT signaling pathway in tamoxifen exemestane adjuvant multinational pathology study. J Clin Oncol 2014;32:2951-8.

[34] Zardavas D et al. Tumor PIK3CA genotype and prognosis: A pooled analysis of 4,241 patients (pts) with early-stage breast cancer (BC). J Clin Oncol $2015 ; 33$.

[35] Mayer IA, Arteaga CL. PIK3CA activating mutations: a discordant role in early versus advanced hormone-dependent estrogen receptor-positive breast cancer? J Clin Oncol 2014;32:2932-4.

[36] Campbell RA et al. Phosphatidylinositol 3-kinase/AKT-mediated activation of estrogen receptor alpha: a new model for anti-estrogen resistance. J Biol Chem 2001;276:9817-24.

[37] Bosch A et al. PI3K inhibition results in enhanced estrogen receptor function and dependence in hormone receptor-positive breast cancer. Sci Transl Med 2015; 7:283ra51.

[38] Aleskandarany MA et al. Clinicopathologic and molecular significance of phospho-Akt expression in early invasive breast cancer. Breast Cancer Res Treat 2011:127:407-16.

[39] Andre F et al. Expression patterns and predictive value of phosphorylated AKT in early-stage breast cancer. Ann Oncol 2008;19:315-20.

[40] Hartog $\mathrm{H}$ et al. Divergent effects of insulin-like growth factor-1 receptor expression on prognosis of estrogen receptor positive versus triple negative invasive ductal breast carcinoma. Breast Cancer Res Treat 2011;129:725-36.

[41] Yang SX et al. Prognostic significance of PAKT plus estrogen receptor status in adjuvant cytotoxic treatment of breast cancer. Eur J Cancer (Suppl.) 2012;48:148.

[42] Lopez-Knowles E et al. PI3K pathway activation in breast cancer is associated with the basal-like phenotype and cancer-specific mortality. Int J Cancer 2010;126:1121-31. 
[43] Andreopoulou E, Sparano JA. Chemotherapy in patients with anthracyclineand taxane-pretreated metastatic breast cancer: an overview. Curr Breast Cancer Rep 2013;5:42-50.

[44] Knuefermann $C$ et al. HER2/PI-3K/Akt activation leads to a multidrug resistance in human breast adenocarcinoma cells. Oncogene 2003;22:3205-12.

[45] Li X, Lu Y, Liang K, Liu B, Fan Z. Differential responses to doxorubicin-induced phosphorylation and activation of Akt in human breast cancer cells. Breast Cancer Res 2005;7:R589-97.

[46] Polley MY et al. Statistical and practical considerations for clinical evaluation of predictive biomarkers. J Natl Cancer Inst 2013;105:1677-83.

[47] Liedtke $C$ et al. PIK3CA-activating mutations and chemotherapy sensitivity in stage II-III breast cancer. Breast Cancer Res 2008;10:R27.

[48] Nakayama $S$ et al. Prediction of paclitaxel sensitivity by CDK1 and CDK2 activity in human breast cancer cells. Breast Cancer Res 2009;11:R12.

[49] Mamounas EP et al. Paclitaxel after doxorubicin plus cyclophosphamide as adjuvant chemotherapy for node-positive breast cancer: results from NSABP B-28. J Clin Oncol 2005;23:3686-96.

[50] Yang SX et al. Akt phosphorylation at Ser473 predicts benefit of paclitaxel chemotherapy in node-positive breast cancer. J Clin Oncol 2010;28:2974-81.

[51] Hutchinson L. P-AKT predicts paclitaxel benefit. Nat Rev Clin Oncol 2010;7:423.

[52] Kawase T et al. PH domain-only protein PHLDA3 is a p53-regulated repressor of Akt. Cell 2009;136:535-50.

[53] Asakuma J, Sumitomo M, Asano T, Asano T, Hayakawa M. Selective Akt inactivation and tumor necrosis actor-related apoptosis-inducing ligand sensitization of renal cancer cells by low concentrations of paclitaxel Cancer Res 2003;63:1365-70.

[54] Franke TF, Kaplan DR, Cantley LC. PI3K: downstream AKTion blocks apoptosis. Cell 1997:88:435-7.

[55] Bartlett JM et al. Phosphorylation of AKT pathway proteins is not predictive of benefit of taxane therapy in early breast cancer. Breast Cancer Res Treat 2013;138:773-81.

[56] Ellis P et al. Sequential docetaxel as adjuvant chemotherapy for early breast cancer (TACT): an open-label, phase III, randomised controlled trial. Lancet 2009;373:1681-92.

[57] Henderson IC et al. Improved outcomes from adding sequential paclitaxel but not from escalating doxorubicin dose in an adjuvant chemotherapy regimen for patients with node-positive primary breast cancer. J Clin Oncol 2003:21:976-83.

[58] Bear HD et al. Sequential preoperative or postoperative docetaxel added to preoperative doxorubicin plus cyclophosphamide for operable breast cancer: national surgical adjuvant breast and bowel project protocol B-27. J Clin Oncol 2006:24:2019-27.

[59] Berns $\mathrm{K}$ et al. A functional genetic approach identifies the PI3K pathway as a major determinant of trastuzumab resistance in breast cancer. Cancer Cell 2007:12:395-402.

[60] Eichhorn PJ et al. Phosphatidylinositol 3-kinase hyperactivation results in lapatinib resistance that is reversed by the mTOR/phosphatidylinositol 3 kinase inhibitor NVP-BEZ235. Cancer Res 2008;68:9221-30.

[61] Hanker $A B$ et al. Mutant PIK3CA accelerates HER2-driven transgenic mammary tumors and induces resistance to combinations of anti-HER2 therapies. Proc Natl Acad Sci U S A 2013;110:14372-7.

[62] Pierga JY et al. A multicenter randomized phase II study of sequential epirubicin/cyclophosphamide followed by docetaxel with or without celecoxib or trastuzumab according to HER2 status, as primary chemotherapy for localized invasive breast cancer patients. Breast Cance Res Treat 2010;122:429-37.

[63] Cizkova M et al. Outcome impact of PIK3CA mutations in HER2-positive breast cancer patients treated with trastuzumab. $\mathrm{Br} \mathrm{J}$ Cancer 2013;108:1807-9.

[64] Jensen JD et al. PIK3CA mutations, PTEN, and pHER2 expression and impact on outcome in HER2-positive early-stage breast cancer patients treated with adjuvant chemotherapy and trastuzumab. Ann Oncol 2012;23:2034-42.

[65] Baselga J et al. Biomarker analyses in CLEOPATRA: a phase III, placebocontrolled study of pertuzumab in human epidermal growth factor receptor 2-positive, first-line metastatic breast cancer. J Clin Oncol 2014;32:3753-61.

[66] Esteva FJ et al. PTEN, PIK3CA, p-AKT, and p-p70S6K status: association with trastuzumab response and survival in patients with HER2-positive metastatic breast cancer. Am J Pathol 2010;177:1647-56.

[67] Baselga J et al. Lapatinib with trastuzumab for HER2-positive early breast cancer (NeoALTTO): a randomised, open-label, multicentre, phase 3 trial. Lancet 2012;379:633-40.

[68] Majewski IJ et al. PIK3CA mutations are associated with decreased benefit to neoadjuvant human epidermal growth factor receptor 2-targeted therapies in breast cancer. J Clin Oncol 2015:33:1334-9.

[69] Nuciforo PG et al. Benefit to neoadjuvant anti-human epidermal growth factor receptor 2 (HER2)-targeted therapies in HER2-positive primary breast cancer is independent of phosphatase and tensin homolog deleted from chromosome 10 (PTEN) status. Ann Oncol 2015;26:1494-500.

[70] Untch $\mathrm{M}$ et al. Neoadjuvant treatment with trastuzumab in HER2-positive breast cancer: results from the GeparQuattro study. J Clin Oncol 2010;28:2024-31.

[71] von Minckwitz G et al. Survival after neoadjuvant chemotherapy with or without bevacizumab or everolimus for HER2-negative primary breast cance (GBG 44-GeparQuinto)dagger. Ann Oncol 2014;25:2363-72.
[72] von Minckwitz G et al. Neoadjuvant carboplatin in patients with triplenegative and HER2-positive early breast cancer (GeparSixto; GBG 66): a randomised phase 2 trial. Lancet Oncol 2014;15:747-56.

[73] Loibl S et al. PIK3CA mutations are associated with lower rates of pathologic complete response to anti-human epidermal growth factor receptor 2 (HER2) therapy in primary HER2-overexpressing breast cancer. J Clin Oncol 2014;32:3212-20.

[74] Henry NL, Schott AF, Hayes DF. Assessment of PIK3CA mutations in human epidermal growth factor receptor 2-positive breast cancer: clinical validity but not utility. J Clin Oncol 2014;32:3207-9.

[75] Guarneri V et al. Preoperative chemotherapy plus trastuzumab, lapatinib, or both in human epidermal growth factor receptor 2-positive operable breast cancer: results of the randomized phase II CHER-LOB study. J Clin Oncol 2012;30:1989-95.

[76] Guarneri V et al. Prospective biomarker analysis of the randomized CHER-LOB study evaluating the dual anti-HER2 treatment with trastuzumab and lapatinib plus chemotherapy as neoadjuvant therapy for HER2-positive breast cancer. Oncologist 2015.

[77] Loibl S et al. Correlation of PIK3CA mutation with pathological complete response in primary HER2-positive breast cancer: combined analysis of 967 patients from three prospective clinical trials. J Clin Oncol 2015;33(Suppl). Abstr 511.

[78] Slamon DJ et al. Predictive biomarkers of everolimus efficacy in HER2+ advanced breast cancer: Combined exploratory analysis from BOLERO-1 and BOLERO-3. J Clin Oncol 2015;33(suppl). abstr 512.

[79] Hurvitz SA et al. Combination of everolimus with trastuzumab plus paclitaxel as first-line treatment for patients with HER2-positive advanced breast cancer (BOLERO-1): a phase 3, randomised, double-blind, multicentre trial. Lancet Oncol 2015;16:816-29.

[80] Andre $\mathrm{F}$ et al. Everolimus for women with trastuzumab-resistant, HER2positive, advanced breast cancer (BOLERO-3): a randomised, double-blind, placebo-controlled phase 3 trial. Lancet Oncol 2014;15:580-91.

[81] Joensuu $\mathrm{H}$ et al. Adjuvant docetaxel or vinorelbine with or without trastuzumab for breast cancer. N Engl J Med 2006;354:809-20.

[82] Loi $\mathrm{S}$ et al. Somatic mutation profiling and associations with prognosis and trastuzumab benefit in early breast cancer. J Natl Cancer Inst 2013:105:960-7.

[83] Pogue-Geile KL et al. Intrinsic subtypes, PIK3CA mutation, and the degree of benefit from adjuvant trastuzumab in the NSABP B-31 trial. J Clin Oncol 2015;33:1340-7.

[84] Eiermann W et al. Phase III study of doxorubicin/cyclophosphamide with concomitant versus sequential docetaxel as adjuvant treatment in patients with human epidermal growth factor receptor 2-normal, node-positive breast cancer: BCIRG-005 trial. J Clin Oncol 2011;29:3877-84.

[85] Stern HM et al. PTEN loss is associated with worse outcome in HER2amplified breast cancer patients but is not associated with trastuzumab resistance. Clin Cancer Res 2015;21:2065-74.

[86] Baselga J et al. Relationship between tumor biomarkers (BM) and efficacy in EMILIA, a phase III study of trastuzumab emtansine (T-DM1) in HER2positive metastatic breast cancer (MBC). Cancer Res 2013(supple). abstr LB63.

[87] Anderson WF et al. Human epidermal growth factor receptor-2 and estrogen receptor expression, a demonstration project using the residual tissue repository of the Surveillance, Epidemiology, and End Results (SEER) program. Breast Cancer Res Treat 2009;113:189-96.

[88] Early Breast Cancer Trialists' Collaborative G et al. Comparisons between different polychemotherapy regimens for early breast cancer: meta-analyses of long-term outcome among 100,000 women in 123 randomised trials. Lancet 2012;379:432-44.

[89] MacKeigan JP et al. Inactivation of the antiapoptotic phosphatidylinositol 3kinase-Akt pathway by the combined treatment of taxol and mitogenactivated protein kinase kinase inhibition. Clin Cancer Res 2002;8:2091-9.

[90] Nakashio A, Fujita N, Rokudai S, Sato S, Tsuruo T. Prevention of phosphatidylinositol 3'-kinase-Akt survival signaling pathway during topotecan-induced apoptosis. Cancer Res 2000;60:5303-9.

[91] Ramos J, Sirisawad M, Miller R, Naumovski L. Motexafin gadolinium modulates levels of phosphorylated Akt and synergizes with inhibitors of Akt phosphorylation. Mol Cancer Ther 2006;5:1176-82.

[92] O'Brien NA et al. Activated phosphoinositide 3-kinase/AKT signaling confers resistance to trastuzumab but not lapatinib. Mol Cancer Ther 2010;9:1489-502.

[93] Generali D et al. Down-regulation of phosphatidylinositol 3'-kinase/ AKT/molecular target of rapamycin metabolic pathway by primary letrozole-based therapy in human breast cancer. Clin Cancer Res 2008:14:2673-80.

[94] Barbareschi M et al. Different prognostic roles of mutations in the helical and kinase domains of the PIK3CA gene in breast carcinomas. Clin Cancer Res 2007;13:6064-9.

[95] Dupont Jensen J et al. PIK3CA mutations may be discordant between primary and corresponding metastatic disease in breast cancer. Clin Cancer Res 2011;17:667-77.

[96] Ramirez-Ardila DE et al. Hotspot mutations in PIK3CA associate with first-line treatment outcome for aromatase inhibitors but not for tamoxifen. Breast Cancer Res Treat 2013;139:39-49.

[97] Beelen K et al. PIK3CA mutations, phosphatase and tensin homolog, human epidermal growth factor receptor 2 , and insulin-like growth factor 1 receptor 
and adjuvant tamoxifen resistance in postmenopausal breast cancer patients. Breast Cancer Res 2014;16:R13.

[98] Stal O et al. Akt kinases in breast cancer and the results of adjuvant therapy. Breast Cancer Res 2003;5:R37-44.

[99] Kirkegaard T et al. AKT activation predicts outcome in breast cancer patients treated with tamoxifen. J Pathol 2005;207:139-46.

[100] Cicenas J et al. Increased level of phosphorylated akt measured by chemiluminescence-linked immunosorbent assay is a predictor of poor prognosis in primary breast cancer overexpressing ErbB-2. Breast Cancer Res 2005; 7:R394-401.
[101] Tokunaga E et al. Activation of PI3K/Akt signaling and hormone resistance in breast cancer. Breast Cancer 2006;13:137-44.

[102] Cizkova M et al. PIK3CA mutation impact on survival in breast cancer patients and in ERalpha, PR and ERBB2-based subgroups. Breast Cancer Res 2012;14 R28.

[103] Bostner J et al. Activation of Akt, mTOR, and the estrogen receptor as a signature to predict tamoxifen treatment benefit. Breast Cancer Res Treat 2013;137:397-406. 